\title{
Voluntary Exercise May Activate Components of Pro-Survival RISK Pathway in the Rat Heart and Potentially Modify Cell Proliferation in the Myocardium
}

\author{
L. LONEK ${ }^{1}$, A. PUHOVA ${ }^{2}$, L. GRIECSOVA-KINDERNAY ${ }^{1}$, S. P. PATEL ${ }^{1,3}$, V. ZOHDI $^{4}$, \\ D. JEZOVA ${ }^{2}$, T. RAVINGEROVA ${ }^{1}$
}

${ }^{1}$ Institute for Heart Research, Centre of Experimental Medicine, Slovak Academy of Sciences, Bratislava, Slovak Republic, ${ }^{2}$ Institute of Experimental Endocrinology, Biomedical Research Center, Slovak Academy of Sciences, Bratislava, Slovak Republic, ${ }^{3}$ The M. S. University of Baroda, Vadodara, Gujarat, India, ${ }^{4}$ Faculty of Medicine, Comenius University of Bratislava, Slovak Republic

Received April 8, 2019

Accepted May 7, 2019

Epub Ahead of Print June 6, 2019

\section{Summary}

Although physical exercise is known to reduce size of infarction, incidence of ventricular arrhythmias, and to improve heart function, molecular mechanisms of this protection are not fully elucidated. We explored the hypothesis that voluntary running, similar to adaptive interventions, such as ischemic or remote preconditioning, may activate components of pro-survival (RISK) pathway and potentially modify cell proliferation. Sprague-Dawley adult male rats freely exercised for 23 days in cages equipped with running wheels, while sedentary controls were housed in standard cages. After 23 days, left ventricular (LV) myocardial tissue samples were collected for the detection of expression and activation of RISK proteins (WB). The day before, a marker of cell proliferation 5-bromo-2'-deoxyuridine (BrdU) was given to all animals to detect its incorporation into DNA of the LV cells (ELISA). Running increased phosphorylation (activation) of Akt, as well as the levels of PKCE and phospho-ERK1/2, whereas BrdU incorporation into DNA was unchanged. In contrast, exercise promoted pro-apoptotic signaling - enhanced $\mathrm{Bax} / \mathrm{Bcl}-2$ ratio and activation of GSK-3 $\beta$ kinase. Results suggest that in the rat myocardium adapted to physical load, natural cardioprotective processes associated with physiological hypertrophy are stimulated, while cell proliferation is not modified. Up-regulation of pro-apoptotic markers indicates potential induction of cell death mechanisms that might lead to maladaptation in the longterm.

\author{
Key words \\ Voluntary running - Exercise-induced preconditioning • \\ Cardioprotection

\section{Corresponding author} \\ T. Ravingerová, Institute for Heart Research, Centre of \\ Experimental Medicine, Slovak Academy of Sciences, Dúbravská \\ cesta 9, 84104 Bratislava, Slovak Republic. E-mail: \\ usrdravi@savba.sk
}

\section{Introduction}

Ischemic heart disease (IHD) and acute myocardial infarction (AMI) often followed by heart failure still remain the major causes of mortality in the developed world (Braunwald 2013). Restoration of blood flow in the ischemic myocardium is a prerequisite of its salvage, however, it can paradoxically result in cell death: a phenomenon termed ischemia/reperfusion (I/R) injury (Hausenloy and Yellon 2013). Despite advanced pharmacotherapy, interventional cardiology (PPCI) and coronary artery bypass grafting (CABG) surgery, there is a substantial need of searching for novel approaches that could specifically address repair of damaged heart given limited endogenous regeneration of cardiomyocytes in adults (Zhang et al. 2010).

Ischemic preconditioning (IPC) based on the 
principle that short-term cardiac adaptation to a moderate stress increases heart resistance to a subsequent sustained stress is a very robust form of innate cardioprotection observed in all animal species including humans (Yellon and Downey 2003). Unfortunately, clinical application of classical IPC is limited to planned interventions (Hausenloy and Yellon 2007). Nevertheless, protection against $\mathrm{I} / \mathrm{R}$ injury can be rendered by other "conditioning" interventions, such as pharmacological PC (Matejíková et al. 2009, Bulluck et al. 2016) or "remote" PC (RPC), in which adaptive stimulus applied in any organ confers protection to other, distant organs/tissues (Tapuria et al. 2008, Heusch 2015, Liang et al. 2015). In particular, non-invasive mode of RPC, limb PC (Wu et al. 2011, Ravingerova et al. 2016), has a potential to be implemented in clinical conditions, e.g., in patients with AMI prior to PPCI or CABG (Cao et al. 2018).

One of the non-ischemic forms of "conditioning" is exercise (Wojcik et al. 2018). General beneficial effects of exercise on cardiovascular system have been well characterized, and it is suggested to improve myocardial ischemic tolerance not only indirectly via reduction of cardiovascular risk factors, such as obesity, hypertension or hyperglycemia, but through a direct effect on the myocardium (Demirel et al. 2001, Mora et al. 2007). Different protocols of exercise including controlled and free running have been shown to induce PC-like protection (Quindry and Hamilton 2013, Marongiu and Crisafulli 2014), in particular, anti-infarct (Brown et al. 2003) and anti-arrhythmic effects (Vegh and Parratt 2005, Hu et al. 2019). Specific mechanisms involved in exercise-induced PC are still not completely clear (Borges and Lessa 2015), but they are suggested to be common with other forms of "conditioning" and act through the pathways shared by IPC and RPC (Alleman et al. 2015, Wojcik et al. 2018, Hu et al. 2019).

Although adult mammalian heart has been long considered as a post-mitotic organ with a limited regenerative capacity, physiological stimuli such as exercise can also elicit cardiac growth (Konhilas et al. 2004, Luckey et al. 2017) associated with new cardiomyocytes formation (Waring et al. 2014). On the other hand, exposure to stressors may reduce cell proliferation in the heart (Babic et al. 2012).

The present study aimed to verify the hypothesis that 1) sub-chronic voluntary running may stimulate cell signaling mechanism in the rat heart known as Reperfusion Injury Salvage Kinase (RISK) pathway (Hausenloy and Yellon 2007) involved in cardioprotection by IPC and RPC, 2) exposure to such form of stress may modify cell proliferation in the myocardium.

\section{Material and Methods}

Sixteen male Sprague-Dawley rats weighing 300-350g (Velaz, Prague, Czech Republic) were housed under standard conditions with a constant $12 \mathrm{~h}$ light/12 h dark cycle (lights on at 6:00 h), and temperature $22^{\circ} \mathrm{C} \pm$ $2{ }^{\circ} \mathrm{C}$. Animals were fed a standard pellet chow with an access to tap water ad libitum. All experiments were conducted in accordance with the "Guide for the Care and Use of Laboratory Animals" published by the US National Institutes of Health (NIH) (Guide, NRC 2011) and approved by the Animal Health and Welfare Division of the State Veterinary and Food Administration of the Slovak Republic and the Animal Care Committee of the CEM SAS.

Animals were randomly divided into groups of Run, where animals freely exercised for 23 days in cages equipped with running wheels with distance control (Activity Wheel for Rats, Animalab, CR) and a group of sedentary controls placed in standard cages (Graban et al. 2017, Dremencov et al. 2017). In both groups, body weight was monitored once a week, and running distance in exercising rats was measured daily. On the day 22 , all animals were injected with 5-bromo-2'-deoxyuridine (BrdU), a marker of cell proliferation, given twice (100 mg/kg, i.p.). The interval between two injections was 4 hours. Seventeen hours after the second BrdU injection, animals were quickly decapitated with a guillotine. The samples of left ventricular (LV) tissue were quickly removed from the rats of both groups, frozen in liquid nitrogen and stored at $-70^{\circ} \mathrm{C}$ until analysis.

\section{BrdU incorporation into DNA}

DNA was extracted from the cells of LV tissue using TRIzol® Reagent (Life technologies, CA, USA, $1 \mathrm{ml} / 1 \mathrm{mg}$ tissue sample) according to the freely available online protocol:

http://genome-www.stanford.edu/DFSP/materials.shtml. BrdU incorporation into the DNA was measured by ELISA method as described previously (Babic et al. 2012). Shortly, 96-well microtitre plates were coated overnight at $4{ }^{\circ} \mathrm{C}$ with a solution of the anti-BrdU antibody (Roche, $5 \mu \mathrm{g} / \mathrm{ml}, 100 \mu \mathrm{l} /$ well) in carbonate buffer, $\mathrm{pH}$ 9.6. This was followed by blocking with 
bovine serum albumin and washing. The extracts of DNA were added and incubated at room temperature. After washing and 120-min incubation with secondary antibody (Anti-BrdU- POD clone BMG -6H8, Roche, 0,2 U/ml, $125 \mu \mathrm{l} / \mathrm{well}$ ), the plates were washed again. 3,3',5,5'tetramethylbenzidine (TMB) substrate (Roche, Germany) was added for $15 \mathrm{~min}$. The reaction was then stopped with $\mathrm{H}_{2} \mathrm{SO}_{4}$. Peroxidase activity (amount of $\mathrm{BrdU}$ in the DNA sample) has been determined spectrophotometrically at $450 \mathrm{~nm}$.

\section{Electrophoresis and Western blot analysis}

Protein levels were determined in the homogenates of LV tissue as described by Griecsová et al. (2015). Samples of the protein fractions containing equivalent amounts of proteins per lane ( $70 \mu \mathrm{g}$ per lane) were separated by $10 \%$ SDS-PAGE gel electrophoresis. For Western blot assays, proteins were transferred to a nitrocellulose membrane. The quality of the transfer was controlled by Ponceau S staining of membranes after transfer. Specific antibodies (from Santa Cruz, Cell Signaling Technology and Abcam) were used for the primary immunodetection of the selected proteins of RISK cascade, protein kinase B (Akt), protein kinase $\mathrm{C} \varepsilon$ (PKC $\varepsilon$ ), extracellular signal-regulated kinases $1 / 2$ (ERK1/2), glycogen synthase kinase-3 beta (GSK-3 $\beta$ ), of pro- and anti-apoptotic proteins (Bax and $\mathrm{Bcl}-2$, respectively), and nuclear factor NF-кB. Peroxidaselabelled anti-rabbit and anti-mouse immunoglobulin was used as the secondary antibody. Enhanced chemiluminescence (ECL) method was used for the visualization of proteins. Optical density of individual bands was analyzed by Carestream Molecular Imaging Software (version 5.0, New Haven, CT, USA) and normalized to glyceraldehyde-3-phospate dehydrogenase (GAPDH) as an internal control.

\section{Statistical analysis}

The data were expressed as means \pm SEM. Student's $t$-test was used for comparison of differences in variables between the groups using GraphPad Prism 6 software (GraphPad, La Jolla, USA). Results were considered significant at $\mathrm{P}<0.05$.

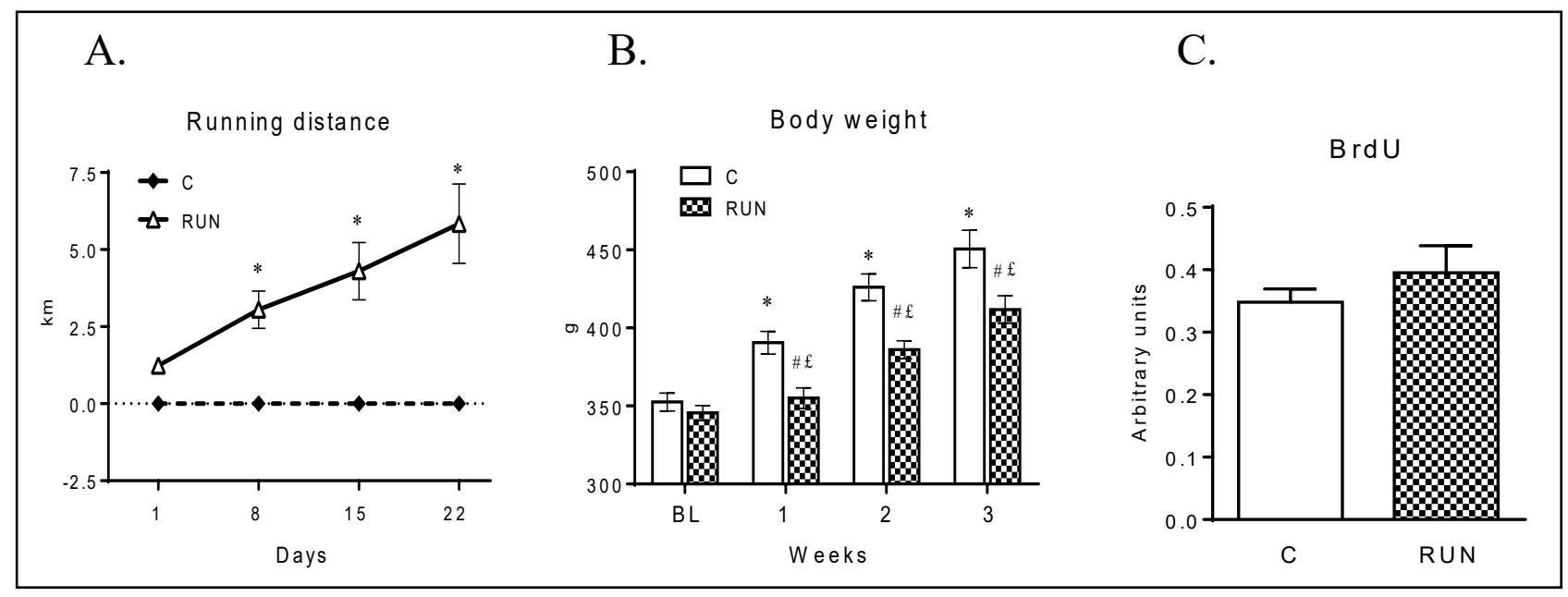

Fig. 1. Running distance, body weight and myocardial cell proliferation in 3 weeks voluntary running rats. C - control sedentary rats; RUN - exercising animals. A. Running distance expressed as a daily distance/per rat. Values are means \pm S.E.M. from 8 rats per group. $* \mathrm{P}<0.05$ vs. baseline values at day 1 . B. Effect of free running on the body weight of sedentary and exercising rats. Values are means \pm S.E.M. from 8 animals per group. ${ }^{*} P<0.05$ vs. baseline values; ${ }^{\#} \mathrm{P}<0.05$ vs. sedentary controls at baseline; ${ }^{£} \mathrm{P}<0.05$ exercising vs. sedentary rats. C. Incorporation of BrdU (5-bromo-2'-deoxyuridine) into the cells of LV (in arbitrary units). Values are means \pm S.E.M. from 8 hearts per group.

\section{Results}

From the beginning of the experiment, exercising rats constantly increased their running activity that reached its maximum on 22nd day (mean running distance $5.8 \pm 1.3 \mathrm{~km}$ ) (Fig. 1A), in contrast to their nonrunning sedentary counterparts. Animals of both groups gradually gained weight over three weeks of experimental protocol, however, this was more pronounced in nonrunners. Body weight of the running rats was significantly lower than in the non-running animals starting from the first week of the experiment up to its end (Fig. 1B). Cell proliferation as detected by incorporation of BrdU into DNA in the cardiomyocytes 
of LV was neither compromised nor increased in the hearts of the exercising rats as compared with its intensity in the hearts of sedentary controls (Fig. 1C).

On the other hand, we observed significant changes in the protein levels and activation of several components of the RISK pathway in the hearts of free running rats as compared to sedentary controls (Fig. 2). Activation of RISK pathway proteins was manifested by a significant $(\mathrm{P}<0.05)$ increase in the phosphorylation (and activation) of protein kinase B (Akt) expressed as a ratio of phospho-Akt and total Akt (Fig. 2A), by enhanced expression of PKCE (Fig. 2B) and markedly increased levels of phospho-ERK1/2 (Fig. 2C) in the group of exercising rats. In contrast, phosphorylation (and inhibition) of GSK-3 $\beta$ expressed as a ratio of phosphoGSK-3 $\beta$ and total GSK-3 $\beta$ was significantly lower in the RUN group (Fig. 2D). That was linked with a significantly increased ratio of proapoptotic (Bax) and antiapoptotic $(\mathrm{Bcl}-2)$ proteins $(\mathrm{Bax} / \mathrm{Bcl}-2)$ as compared with that in the group of sedentary controls (Fig. 2E). Furthermore, exercise significantly enhanced protein levels of NF-kB indicating potential proinflammatory response (Fig. 2F).
A.

Phospho-Akt

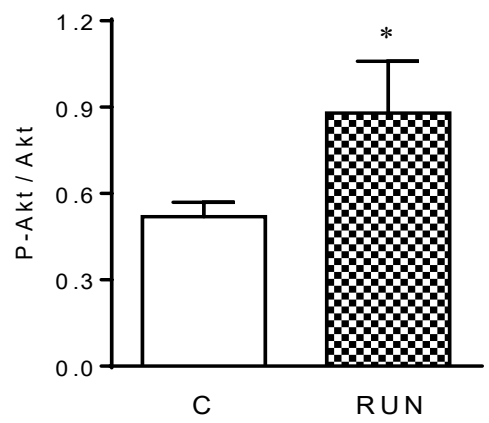

D.

GSK $-3 \beta$

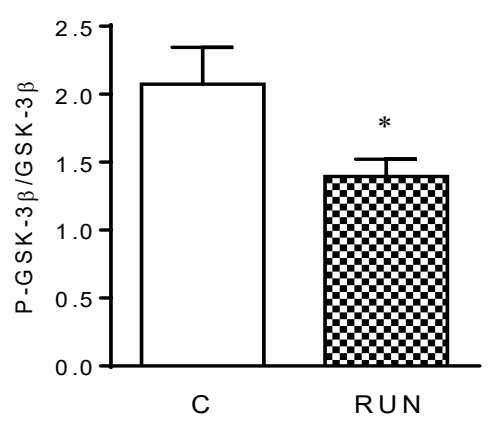

B.

$\mathrm{PKC} \varepsilon$

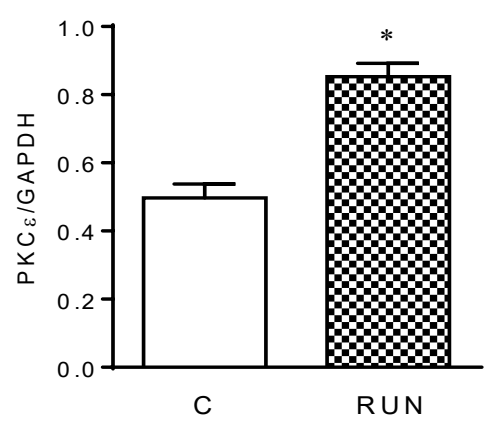

E.

$\mathrm{Bax} / \mathrm{B} \mathrm{cl}-2$

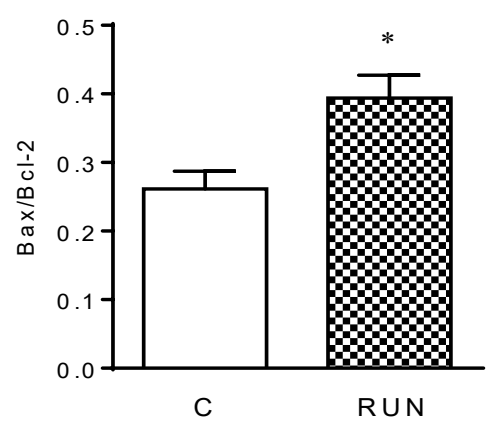

C.

Phospho-ERK1/2

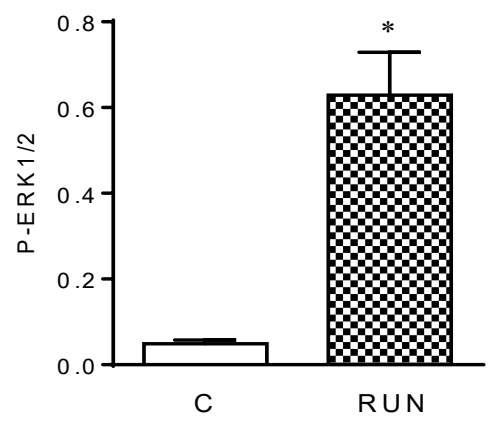

F.

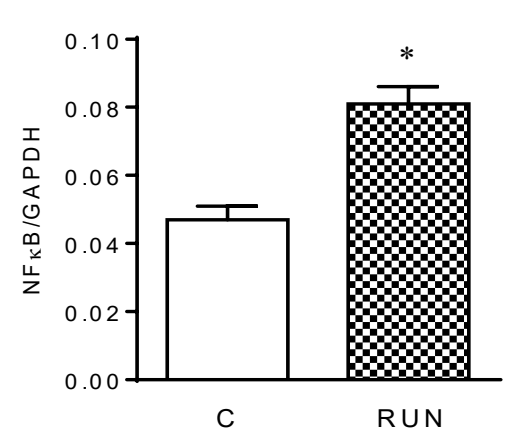

Fig. 2. Effect of 3-week voluntary running on the activation of RISK pathway in the rat myocardium. A. Ratio of phosphorylated (activated) Akt and total Akt in the hearts of sedentary controls and exercising rats. B. Levels of PKCE in the hearts of sedentary controls and exercising rats. C. Levels of phosphorylated ERK1/2 in the hearts of sedentary controls and exercising rats. D. Effects of

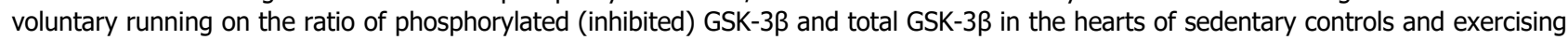
rats. E. Ratio of the levels of pro-apoptotic (Bax) and anti-apoptotic ( $\mathrm{BCl}-2)$ proteins in the hearts of sedentary controls and exercising rats. F. Protein levels of nuclear factor kappa B (NF-KB) in the hearts of sedentary controls and exercising rats. Protein levels are presented as means \pm S.E.M of 8 hearts per group normalized to the levels of GAPDH. $* P<0.05$ relative to sedentary controls. 


\section{Discussion}

The aim of the present study was to test the hypothesis that voluntary wheel running induces enhancement of cell proliferation in the rat heart associated with activation of cell survival cascades involved in the cardioprotective effects of various forms of preconditioning and long-lasting adaptation. We have shown that 3-week uninterrupted physical activity on a voluntary basis evoked significant and stable weight loss in the running animals (Fig. 1A, B) which is considered as a generally beneficial factor associated with survival rate after AMI (Paffenbarger et al. 1993). In addition, in a protocol of free running Wistar rats, we have further observed not only similar weight loss in the runners, but also a lower heart weight (HW) in this group $(490 \pm 27 \mathrm{mg}$ vs. $581 \pm 21 \mathrm{mg}$ in controls, $\mathrm{P}<0.05)$. Accordingly, relative $\mathrm{HW}$ normalized to $\mathrm{BW}$ did not differ between the groups of sedentary and exercising animals indicating the absence of hypertrophy in this phase of exercise (not published).

Interestingly, free running did not reduce BrdU-dependent cell proliferation in the LV (Fig. 1C) that might be induced by a moderate stress experienced by animals (Babic et al. 2012). On the other hand, moderate exercise has been shown to increase cell proliferation in the heart (Waring et al. 2014). In our experimental protocol, cell proliferation in the LV was not enhanced, however, this may be encountered in more intensive (controlled running on a treadmill) and longer lasting ( $>4$ weeks) protocols of exercise manifested by both, LV hypertrophy and formation of new cardiomyocytes (Waring et al. 2014).

The mechanisms of exercise-induced physiological hypertrophy involve stimulation of the release of growth hormones and factors that facilitate the growth response of the heart. These processes activate a number of cellular receptors and intracellular signaling pathways including the IGF1-PI3K-Akt signaling pathway (Maillet et al. 2013). Among those, PKC isozymes play a central role in the regulation of growth, hypertrophy, and act as mediators of signal transduction pathways (Singh et al. 2017). ERK1/2 kinases from the MAP-kinase superfamily are activated in cardiac myocytes in response to every type of stress and, in most cases, associated with induction of the hypertrophic response (Bueno and Molkentin 2002). On the other hand, these kinases, in particular, PI3K/Akt, PKCE and ERK1/2, besides their role in hypertrophic response, also play a positive role in pro-survival mechanisms activated by various "conditioning" interventions including adaptation to chronic hypoxia and leading to infarct size limitation (Hausenloy and Yellon 2007, Ravingerová et al. 2007, Heusch 2015, Hu et al. 2019). Our study shows that, similar to IPC or RPC, subchronic 3-week voluntary running stimulates the elevation of the expression and/or activation of the components of the RISK cell survival proteins (Akt, PKC $\varepsilon$ and ERK1/2) as compared with their levels in non-running controls (Fig. 2A, B, C), and thus, sheds more light on the mechanisms of exercise-induced preconditioning.

On the contrary, decreased phosphorylation (and activation) of GSK-3 $\beta$ as one of the crucial steps in the cascade of $\mathrm{I} / \mathrm{R}$ injury (Fig. 2D) indicates that along with activation of cell protection mechanisms, relatively short period of uninterrupted running is capable to promote cell death mechanisms. Failure of GSK-3 $\beta$ inhibition facilitates the opening of mitochondrial permeability transition pore (mPTP) as a final process in the scenario of I/R injury leading to apoptosis and cell death (Heusch 2015, Li et al. 2018). We can thus speculate that 3 weeks of voluntary running in Sprague-Dawley rats is not a sufficient duration or intensity of the stimulus to suppress the activity of GSK-3 $\beta$.

Moderate exercise training has been shown to attenuate apoptosis in skeletal and cardiac muscles. Siu et al. (2004) have demonstrated enhanced protein levels of antiapoptotic protein Bcl-2 positively correlating with significantly greater HSP70 protein levels in ventricles of young rats exercising on treadmill, and inverse relationship between HSP70 and Bax mRNA levels in exercise-trained muscles. In our study, Bcl-2 protein levels did not differ between the groups, while Bax levels were more than two-fold higher in the RUN group and subsequently, Bax/Bcl-2 ratio in this group was significantly increased as compared to that in sedentary controls (Fig. 2E). These controversies in the results could be related to age-dependent differences in the experimental animals, as well as to the differences in the intensity, type and duration of the exercise protocols as the main determinants of the strength of protective adaptive response (Esposito et al. 2011, Waring et al. 2014, Wojcik et al. 2018).

In addition, 3-week running increased protein levels of nuclear factor NF- $\mathrm{BB}$ (Fig. 2F). This pathway has been long considered to play a dominant role the processes of inflammation triggerred by proinflammatory 
cytokines such as interleukin 1 (IL-1) and tumor necrosis factor $\alpha$ (TNF- $\alpha)$, as well as to play a role in the expression of other proinflamatory genes including cytokines, chemokines, and adhesion molecules (Lawrence 2009). Activation of NF- $\kappa$ B has been also shown to contribute to the processes of myocardial I/R, such as oxidative stress, apoptosis, adverse remodelling (Hamid et al. 2011) and infarct development (Gray et al. 2017). However, the contribution of NF- $\kappa B$ to apoptotic cell death still remains inconclusive, since there are studies showing its dual role, and that under certain conditions, NF- $\mathrm{KB}$ signaling results in cardiomyocytes survival (Dhingra et al. 2013). Furthermore, the role of $\mathrm{NF}-\kappa \mathrm{B}$ in cardioprotection in the late second phase of IPC has been well established (Xuan et al. 1999). It has been shown that the late phase of IPC is associated with NF- $\kappa \mathrm{B}$-dependent cardioprotective gene programs, in particular, with a gene expression of heat shock proteins (Tranter et al. 2010). However, the role of NF- $\mathrm{BB}$ in the mechanisms of exercise-induced PC, as well as its interaction with pro-survival RISK pathway proteins require further exploration.

\section{Study limitation}

In this study, free running did not modify BrdU-dependent cell proliferation in the left ventricle. However, other studies demonstrated that besides new cardiomyocytes formation, exercise training may also stimulate proliferation of other cell types, e.g., capillary cells, contributing to the physiological remodelling of the heart (Waring et al. 2014). This may be quantified by immunehistochemistry and could be performed in our further studies.

\section{Conclusions}

In the myocardium adapted to the physical load after 3 weeks of moderate exercise training, the cell proliferation is not yet modified, despite induction of natural cardioprotective processes associated with physiological hypertrophy. However, these results suggest that long-term uninterrupted exercise may be detrimental and might potentially lead to maladaptation due to chronic activation of kinases of RISK cascade associated with hypertrophic response. This is supported by the simultaneous up-regulation of proapoptotic and proinflammatory markers. The study sheds light on some potential mechanisms of exercise-induced preconditioning, however, further research is needed to ultimately understand the advantages and disadvantages of short or longer lasting exercise, as well as its intensity.

\section{Conflict of Interest}

There is no conflict of interest.

\section{Acknowledgements}

The authors are thankful to Dr. V. Farkašová, Dr. B. Szeiffová Bačová and Mrs. I. Formánková, for their valuable advices and excellent technical assistance. This study was supported by grants of the Slovak Grant Agency VEGA SR 2/0141/18, 2/0151/17, 2/0042/19, APVV-15-0607, ITMS 26230120009 and COST EU Cardioprotection action CA16225.

\section{References}

ALLEMAN RJ, STEWART LM, TSANG AM, BROWN DA: Why does exercise "trigger" adaptive protective responses in the heart? Dose-Response 13: 1-19, 2015.

BABIC S, ONDREJCAKOVA M, BAKOS J, RACEKOVA E, JEZOVA D: Cell proliferation in the hippocampus and in the heart is modified by exposure to repeated stress and treatment with memantine. J Psychiatr Res 46: 526-532, 2012.

BORGES JP, LESSA A: Mechanisms involved in exercise-induced cardioprotection: a systematic review. Arq Bras Cardiol 105: 71-81, 2015.

BRAUNWALD E: Heart failure JACC Heart Fail 1: 1-20, 2013.

BROWN D, JEW KN, SPARAGNA GC, MUSCH TI, AND MOORE RL: Exercise training preserves coronary flow and reduces infarct size after ischemia-reperfusion in rat heart. $J$ Appl Physiol 95: 2510-2518, 2003.

BUENO OF, MOLKENTIN JD: Involvement of extracellular signal-regulated kinases $1 / 2$ in cardiac hypertrophy and cell death. Circ Res 91: 776-781, 2002.

BULLUCK H, YELLON DM, HAUSENLOY DJ: Reducing myocardial infarct size: challenges and future opportunities. Heart 102: 341-348, 2016. 
CAO B, WANG H, ZHANG C, XIA M, YANG X: Remote ischemic postconditioning (RIPC) of the upper arm results in protection from cardiac ischemia-reperfusion injury following primary percutaneous coronary intervention (PCI) for acute ST-Segment elevation myocardial infarction (STEMI). Med Sci Monit 24: 1017-1026, 2018.

DEMIREL HA, POWERS SK, ZERGEROGLU MA, SHANELY RA, HAMILTON K, COOMBES J, NAITO H: Short-term exercise improves myocardial tolerance to in vivo ischemia-reperfusion in the rat. J Appl Physiol 91: 2205-2212, 2001.

DREMENCOV E, CSATLOSOVA K, DURISOVA B, LAPÍNOVA L, LACINOVA L, JEZOVA D: Effect of physical exercise and acute escitalopram on the excitability of brain monoamine neurons. in vivo electrophysiological study in rats. Int J Neuropsychopharmacol 20: 585-592, 2017.

ESPOSITO F, RONCHI R, MILANO G, MARGONATO V, DI TULLIO S, MARINI M, VEICSTEINAS A, SAMAJA M: Myocardial tolerance to ischemia-reperfusion injury, training intensity and cessation. Eur J Appl Physiol 111: 859-868, 2011

GRABAN J, HLAVACOVA N, JEZOVA D: Increased gene expression of selected vesicular and glial glutamate transporters in the frontal cortex in rats exposed to voluntary wheel running. J Physiol Pharmacol 68: 709-714, 2017.

GRAY CB, SUETOMI T, XIANG S, MISHRA S, BLACKWOOD EA, GLEMBOTSKI CC, MIYAMOTO S, WESTENBRINK BD, BROWN JH: CaMKII $\delta$ subtypes differentially regulate infarct formation following ex vivo myocardial ischemia/reperfusion through NF- $\kappa \mathrm{B}$ and TNF- $\alpha . J$ Mol Cell Cardiol 103: 48-55, 2017.

GRIECSOVÁ L, FARKAŠOVÁ V, GÁBLOVSKÝ I, KHANDELWAL VKM, BERNÁTOVÁ I, TATARKOVÁ Z, KAPLAN P, RAVINGEROVÁ T: Effect of maturation on the resistance of rat hearts against ischemia. study of potential molecular mechanisms. Physiol Res 64 (Suppl 5): S685-S696, 2015.

HAUSENLOY DJ, YELLON DM: Reperfusion injury salvage kinase signalling: taking a RISK for cardioprotection. Heart Fail Rev 12: 217-34, 2007.

HAUSENLOY DJ, YELLON DM: Myocardial ischemia-reperfusion injury: a neglected therapeutic target. $J$ Clin Invest 123: $92-100,2013$

HEUSCH G: Molecular basis of cardioprotection. Signal transduction in ischemic pre-, post-, and remote conditioning. Circ Res 116: 674-699, 2015.

HU Z, LIU J, ZHOU L, TIAN X, ABBOTT GW: AKT and ERK1/2 activation via remote ischemic preconditioning prevents Kcne2-dependent sudden cardiac death. Physiol Rep 7: e13957, 2019.

KONHILAS JP, MAASS AH, LUCKEY SW, STAUFFER BL, OLSON EN, LEINWAND LA: Sex modifies exercise and cardiac adaptation in mice. Am J Physiol. Heart Circ Physiol 287: H2768-2776, 2004.

LAWRENCE T: The nuclear factor NF-кB pathway in inflammation. Cold Spring Harb Perspect Biol 1: a001651, 2009.

LI HX, CUI XL, XUE FS, YANG GZ, LIU YY, LIU Q, LIAO X: Inhibition of glycogen synthase kinase-3 $\beta$ is involved in cardioprotection by $\alpha 7 \mathrm{nAChR}$ agonist and limb remote ischemic postconditionings. Biosci Rep 38: pii: BSR20181315, 2018

LIANG Y, LI YP, HE F, LIU XQ, ZHANG JY: Long-term, regular remote ischemic preconditioning improves endothelial function in patients with coronary heart disease. Braz J Med Biol Res 48: 568-576, 2015.

LUCKEY SW, HAINES CD, KONHILAS JP, LUCZAK ED, MESSMER-KRATZSCH A, LEINWAND LA: Cyclin D2 is a critical mediator of exercise-induced cardiac hypertrophy. Exp Biol Med (Maywood) 242: 1820-1830, 2017.

MAILLET M, VAN BERLO JH, MOLKENTIN JD: Molecular basis of physiological heart growth: fundamental concepts and new players. Nat Rev Mol Cell Biol 14: 38-48, 2013.

MARONGIU E, CRISAFULLI A: Cardioprotection acquired through exercise: the role of ischemic preconditioning. Curr Cardiol Rev 10: 336-348, 2014.

MATEJÍKOVÁ J, KUCHARSKÁ J, PINTÉROVÁ M, PANCZA D, RAVINGEROVÁ T: Protection against ischemiainduced ventricular arrhythmias and myocardial dysfunction conferred by preconditioning in the rat heart: involvement of mitochondrial K(ATP) channels and reactive oxygen species. Physiol Res 58: 9-19, 2009.

MORA S, COOK N, BURING JE, RIDKER PM, LEE IM: Physical activity and reduced risk of cardiovascular events: potential mediating mechanisms. Circulation 116: 2110-2118, 2007. 
PAFFENBARGER RS JR, HYDE RT, WING AL, LEE IM, JUNG DL, KAMPERT JB: The association of changes in physical activity level and other lifestyle characteristics with mortality among men. $N$ Engl J Med 328: 538-545, 1993.

POWERS SK, QUINDRY JC, KAVAZIS AN: Exercise-induced cardioprotection against myocardial ischemiareperfusion injury. Free Radic Biol Med 44: 193-201, 2008.

QUINDRY JC, HAMILTON KL: Exercise and cardiac preconditioning against ischemia reperfusion injury. Curr Cardiol Rev 9: 220-229, 2013.

RAVINGEROVA T, FARKASOVA V, GRIECSOVA L, CARNICKA S, MURARIKOVA M, BARLAKA E, KOLAR F, BARTEKOVA M, LONEK L, SLEZAK J, LAZOU A: Remote preconditioning as a novel "conditioning" approach to repair the broken heart: potential mechanisms and clinical applications. Physiol Res 65 (Suppl. 1): S55-S64, 2016.

RAVINGEROVÁ T, MATEJÍKOVÁ J, NECKÁR J, ANDELOVÁ E, KOLÁR F: Differential role of PI3K/Akt pathway in the infarct size limitation and antiarrhythmic protection in the rat heart. Mol Cell Biochem 297: 111-120, 2007.

SINGH RM, CUMMINGS E, PANTOS C, SINGH J: Protein kinase C and cardiac dysfunction: a review. Heart Fail Rev 22: 843-859, 2017.

SIU PM, BRYNER RW, MARTYN JK, ALWAY SE: Apoptotic adaptations from exercise training in skeletal and cardiac muscles. FASEB J 18: 1150-1152, 2004.

TAPURIA N, KUMAR Y, HABIB MM, ABU AM, SEIFALIAN AM, DAVIDSON BR: Remote ischemic preconditioning: a novel protective method from ischemia reperfusion injury --a review. J Surg Res 150: 304-330, 2008.

TRANTER M, REN X, FORDE T, WILHIDE ME, CHEN J, SARTOR MA, MEDVEDOVIC M, JONES WK: NF-кB driven cardioprotective gene programs; Hsp70.3 and cardioprotection after Late Ischemic Preconditioning. J Mol Cell Cardiol 49: 664-672, 2010.

VEGH A, PARRATT JR: A common mechanism in the protective effects of preconditioning, cardiac pacing and physical exercise against ischemia and reperfusion-induced arrhythmias. Exp Clin Cardiol 10: 200-205, 2005.

WARING CD, VICINANZA C, PAPALAMPROU A, SMITH AJ, PURUSHOTHAMAN S, GOLDSPINK DF, NADAL-GINARD B, TORELLA D, ELLISON GM: The adult heart responds to increased workload with physiologic hypertrophy, cardiac stem cell activation, and new myocyte formation. Eur Heart J 35: 2722-2731, 2014.

WOJCIK B, KNAPP M, GORSKI J: Non-ischemic heart preconditioning. J Physiol Pharmacol 69: 173-184, 2018.

WU YN, YU H, ZHU XH, YUAN HJ, KANG Y, JIAO JJ, GAO WZ, LIU YX, LOU JS: Noninvasive delayed limb ischemic preconditioning attenuates myocardial ischemia-reperfusion injury in rats by a mitochondrial K(ATP) channel-dependent mechanism. Physiol Res 60: 271-279, 2011.

XUAN YT, TANG XL, BANERJEE S, TAKANO H, LI RC, HAN H, QIU Y, LI JJ, BOLLI R: Nuclear factor-kappaB plays an essential role in the late phase of ischemic preconditioning in conscious rabbits. Circ Res 84: 1095-1109, 1999.

YELLON DM, DOWNEY JM: Preconditioning the myocardium: from cellular physiology to clinical cardiology. Physiol Rev 83: 1113-1151, 2003.

ZHANG Y, LI TS, LEE ST, WAWROWSKY KA, CHENG K, GALANG G, MALLIARAS K, ABRAHAM MR, WANG C, MARBÁN E: Dedifferentiation and proliferation of mammalian cardiomyocytes. PLoS One 5: e12559, 2010. 